\title{
Modelling the Environmental Consequences of Fires in Warehouses
}

\author{
S. D. MILES and G. COX
}

Fire Research Station, Borehamwood, Herts WD6 2BL, UK

M. N. CHRISTOLIS, C. A. CHRISTIDOU, A. G. BOUDOUVIS and N. C. MARKATOS

National Technical University of Athens, Zografou Campus,

Athens 15780 , Greece

\begin{abstract}
The paper describes progress in the development of a numerical modelling methodology for predicting the environmental consequences of fires in warehouses. Two separate computational fluid dynamics models have been used to predict the emission of combustion products through warehouse roof openings and then to predict the atmospheric dispersion of the effluent. At this stage of development the dispersion model employs as boundary conditions the outflows, through the roof vents, predicted by the enclosure fire model.

Results are presented for a representative warehouse containing a burning high-rack of storage with the hot gases vented to the external environment through nine roof vents. The key parameters for dispersion modelling are identified, and an example is provided using the emission from the nine roof vents. Further work is identified for the development of a practical hazard analysis tool.
\end{abstract}

KEYWORDS: Computational Fluid Dynamics, Field Model, Warehouse, Dispersion

\section{NOKENCIATURE}

$C=$ concentration of effluent $\left(\mathrm{kg} \mathrm{m}^{-3}\right)$

$\mathbf{E}=$ emission rate of effluent $\left(\mathrm{kg} \mathrm{s}^{-1}\right)$

$\mathbf{F}=$ buoyancy flux $\left(\mathrm{m}^{4} \mathrm{~s}^{-3}\right)$

$\mathrm{g}=$ acceleration due to gravity $\left(\mathrm{m} \mathrm{s}^{-2}\right)$

$\mathbf{K}=$ dimensionless concentration

$\mathrm{L}$ = building height $(\mathrm{m})$

$\mathrm{M}=$ momentum flux $\left(\mathrm{m}^{\mathrm{s}} \mathrm{s}^{-2}\right)$

$\mathrm{U}$ = wind velocity at building height $\left(\mathrm{m} \mathrm{s}^{-1}\right)$

$\mathrm{V}=$ volumetric flow rate $\left(\mathrm{m}^{3} \mathrm{~s}^{-1}\right)$

$\mathrm{w}=$ vertical velocity component $\left(\mathrm{m} \mathrm{s}^{-1}\right)$

$p=\operatorname{density}\left(\mathrm{kg} \mathrm{m}^{-3}\right)$ 
(subscripts)

$\mathrm{a}=$ ambient or atmospheric

$p=$ plume or effluent

\section{TKTRODUCTION}

In 1982 the Commission of the European Communities (CEC) issued Directive 82/501/EEC on the Hajor Accident Hazards of Certain Industrial Activities. often known as the Seveso Directive, after the 1976 accident, it sought to minimise the risk of major accidents arising from industrial activities involving dangerous substances and to limit the resulting consequences of such accidents for man and the environment.

Later accidents at Bhopal and at the Sandoz plant in Switzerland prompted the CEC to extend the scope of this Directive in 1988. Further substances were brought within its scope and greater emphasis was given to the storage of hazardous substances, particularly in warehouses. One consequence of this amendment has been a recognition of the need to develop a robust methodology for conducting major accident hazard analysis for individual installations.

Although relatively simplistic tools [1] are currently available to assist in the evaluation of warehouse fire hazards, these cannot deal with difficult aspects such as complex terrain, multiple roof vents and sprinkler systems.

In many kinds of building, particularly those of public assembly such as covered shopping centres, roof vents allow the products of combustion to be released to the external environment, making the internal environment safer for the occupants and also assisting the fire fighting operation.

For a warehouse containing hazardous substances venting may not be the best strategy. It may be better to seal the building, allowing sprinklers and shortage of air to limit at least the airborne release of toxic materials. of course limiting airborne release may be at the expense of local groundwater contamination. Clearly, evaluation of the most appropriate strategy to employ is not a simple matter. It has even been suggested [2] that it may be preferable to allow a fire to grow unabated such that if the building envelope is eventually breached then the fire plume will have sufficient buoyancy for it to rise high into the atmosphere leading to a broader environmental dispersion of toxic material than would otherwise occur.

This paper describes the application of the field modelling method to both the problem of fire growth within a warehouse and to the subsequent dispersion of combustion products within the atmospheric boundary layer. of particular concern are storages of pesticides and herbicides.

\section{THE DAREHOUSE FIRE}

Warehouse fires present a potentially severe fire hazard due to the high concentration of goods, usually stored in uncompartmented enclosures. Although the risk of ignition may not be particularly great, if such fires do occur in unsprinklered high-rack configurations they can be particularly difficult to extinguish. The 1983 fire at an Army Ordnance Depot in the UK 
exemplified the great difficulties that the fire fighting agencies can experience. This fire, in an unsprinklered warehouse, was responsible for an estimated 1165 million direct property loss and, furthermore, caused asbestos flakes and fibres from the roof construction to be dispersed into the local environment.

With high-rack storage of goods in warehouses the potential for rapid vertical fire spread is clear, and should flames reach the underside of the roof there is the possibility of lateral spread to adjacent racks as a result of heat transfer from hot gases trapped beneath the roof. Lateral spread may also occur due to the spillage of flammable liquid materials from burst containers such as drums and bottles. Although both in-rack and roof-mounted sprinklers are recommended for many general storage areas there still remain a large number of warehouses which have no such protection.

The characteristics of a release of toxic materials into the environment will vary, from relatively small mass flow rates of low buoyancy gases leaking through adventitious ventilation openings, to much larger releases of highly buoyant gases through automatic roof vents, burnt-out skylights or even eventually through complete failure of the building envelope. The interaction of buoyant plumes with the external airflow in the vicinity of the warehouse and with adjacent buildings will determine the degree of dispersion of toxic material into the local environment.

The techniques of Computational Fluid Dynamics (CFD), known in fire science as field modelling, are particularly suitable for application to this problem since they provide a general approach to the theoretical analysis of both enclosure fires and of atmospheric dispersion problems, particularly through complex urban environments. These techniques have been applied here to the warehouse dispersion problem by passing to the external dispersion model, as boundary conditions, predictions for a given fire of the physical variables (density, velocity, temperature, product concentrations etc) at the warehouse openings.

\section{THE PROBLEH STUDIED}

A 'representative' warehouse was selected for the studies. This is shown in Fig 1. The warehouse dimensions are $70 \mathrm{~m}$ long, $30 \mathrm{~m}$ wide and $8 \mathrm{~m}$ high with a flat roof. Two doorway openings, each $4 \mathrm{~m}$ by $4 \mathrm{~m}$, have been placed in one of the long walls, and up to 48 roof ventilation openings, $2 \mathrm{~m}$ by $2 \mathrm{~m}$, have been included. This warehouse is situated within an external calculation domain, $1200 \mathrm{~m}$ by $670 \mathrm{~m}$ in ground area and height $230 \mathrm{~m}$.

Various fire types have been studied including steady, hydrocarbon pool fires situated on the warehouse floor and transient fires developing within high-rack storages. Pool fires may occur when containers of solvent rupture, so that the contents drain into the burning pool below. A typical solvent for pesticides is xylene.

The results presented in this paper were obtained for the representative warehouse with nine roof vents, and containing a growing, cellulose high-rack fire, taken to represent a storage of granular material which does not burn as a pool fire. 


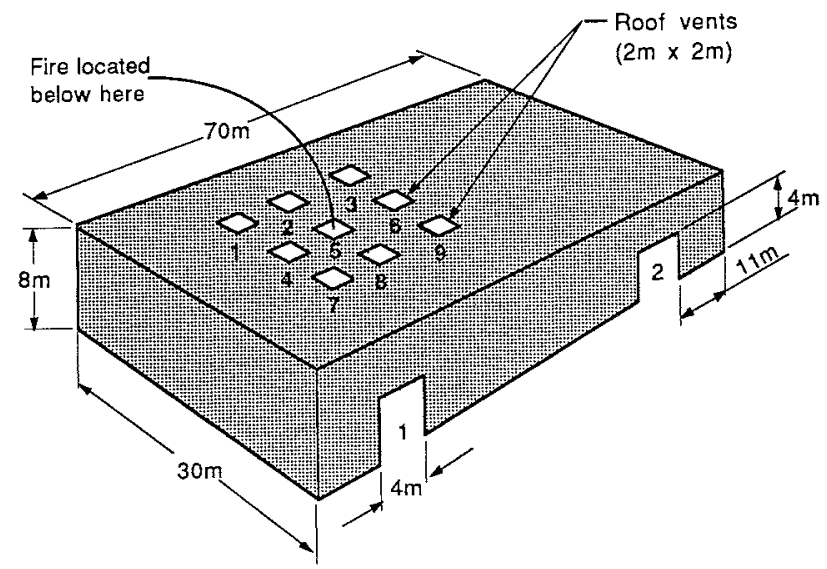

PIGURE 1. Warehouse geometry

Empirical, transient data from fire tests on high-rack storage arrangements have been reported in the literature. Data from one test, reported by You and Kung [3], have been expressed in terms of mass loss and heat release rates over a five minute interval starting from the time of ignition. The actual storage arrangement was a 4-tier rack, with cross sectional area approximately $4 \mathrm{~m}^{2}$, housing a cellulose commodity. Figure 2 shows the heat release curve, which was derived from the experimental values for mass loss rate and effective convective heat. Following an incipient period, the heat release rate rises quickly to $8.5 \mathrm{MW}$ at three minutes.

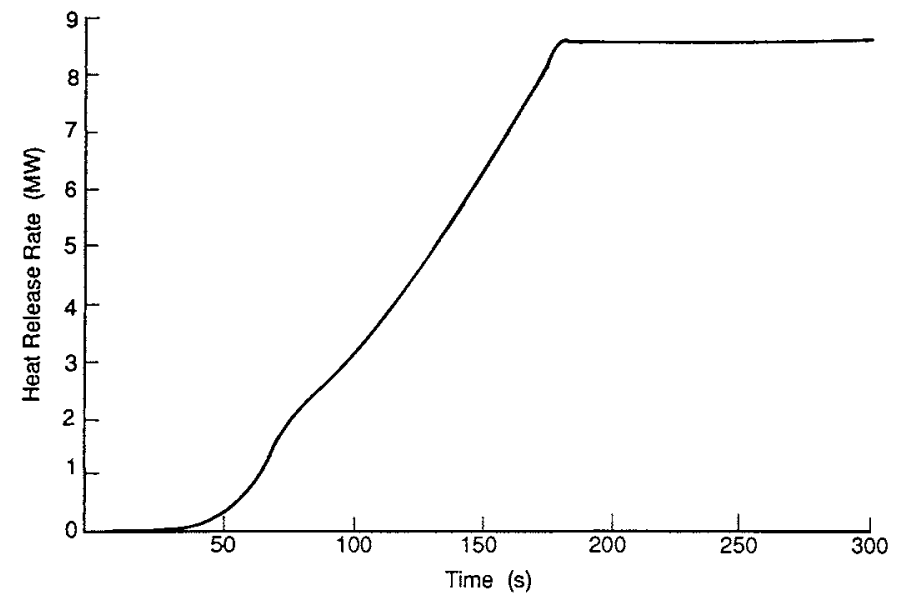

FIGURE 2. Heat release rate for a growing fire in a 4-tier rack of cellulose 
Various venting configurations have been studied including the cases of no venting and of 48 permanently open roof vents. The choice of nine, permanently open, vents represented an intermediate step towards implementing a fully transient simulation with all vents initially closed, and then opening according to the change in local conditions within the warehouse. Figure 1 shows the location of the openings and the fire, and includes the numbering of vents and doors to be referred to in the results.

The atmospheric dispersion model used the outflow data, predicted by the enclosure fire model, at the nine vents five minutes from the start of the fire. A free stream wind velocity of $10 \mathrm{~m} \mathrm{~s}^{-1}$ was applied upstream of the warehouse in the direction parallel to the short (width) sides of the warehouse. At roof height the wind velocity was $6.2 \mathrm{~m} \mathrm{~s}^{-1}$. A flat terrain was assumed.

\section{DETAILS OF THE KODELLING}

Details of the enclosure fire model JASMINE have been described elsewhere [4] and will not be repeated here. Summarising, it employs at its core an early version of PHOENICS to solve, throughout the computational domain, the equations of conservation of mass, momentum, energy and chemical species. Additional fire science sub-models ensure appropriate treatments for buoyant, turbulent combustion and for thermal radiation, chemical kinetics and boundary heat losses.

A transient, JASHINE simulation was performed to predict the conditions, after five minutes, at the vents. Time-steps from one second at the start, to five seconds towards the end, were employed. Approximately $30,000 \mathrm{grid}$ cells were used, with between 4 and 12 cells representing each vent opening. The fire was located below the central vent, identified as vent number 5 in Fig 1 .

The combustion model employed assumed a one step reaction, which for cellulose was represented by the following, simplified equation

$\mathrm{C}_{6} \mathrm{H}_{10} \mathrm{O}_{5}+6 \mathrm{O}_{2} \rightarrow 6 \mathrm{CO}_{2}+5 \mathrm{H}_{2} \mathrm{O}$

It was assumed, as a first approximation, that external wind effects did not influence the conditions inside the warehouse. Hence a quiescent, external atmosphere was imposed for the transient, internal simulation.

The resultant values of the physical variables required for the dispersion model were generated at each vent. This data set included the density, temperature, velocity and product concentrations of the hot emission gases, as well as the turbulence parameters ( $k$ and $\varepsilon$ ). Furthermore, the mass, momentum and buoyancy fluxes were calculated from this data set. The data at the vents and doors were passed on as boundary conditions to the atmospheric dispersion model.

This model also uses PHOENICS, and is based on a methodology described by Markatos et al [5]. As vell as the mass, momentum and heat sources at the nine roof vents, mass sink terms corresponding to the air inflow rates at the door openings were applied. As for JASMINE, the buoyancy forces were treated as impressed body forces in the source term of the vertical momentum equation and in the turbulence model [6]. 
In addition to the specified upstream velocity profile, further boundary conditions were applied at the top and sides of the domain to ensure shear free flow and zero temperature gradients here. The warehouse boundaries for both the enclosure fire model and for the dispersion model vere assumed to be thermally adiabatic with standard wall functions [7] treating momentum losses to the valls. The external domain was discretised into 40,000 grid cells.

The dispersion model was run only in the steady state mode, taking the emission data five minutes from fire ignition to be representative of the steady conditions for that particular fire ( $8.5 \mathrm{KW})$.

\section{RESULIS}

\section{Internal Kodelling}

A selection of the transient results is presented in Figs 3 and 4 together with more detailed results in Table 1 for the simulation at five minutes.

Figure 3 shows the total mass outflow rate of hot emission gases from the roof vents over the five minute period. Plots are shown for the total emission and the individual contribution from the central vent (number 5) above the fire source. Figure 4 contains corresponding plots for the convected heat release rate. Note that the contribution from the central vent, above the fire, peaked at the end of the fire growth phase. The subsequent reduction is attributed to the development of a more uniform hot layer below the ceiling, resulting in a more significant contribution from the neighbouring vents.

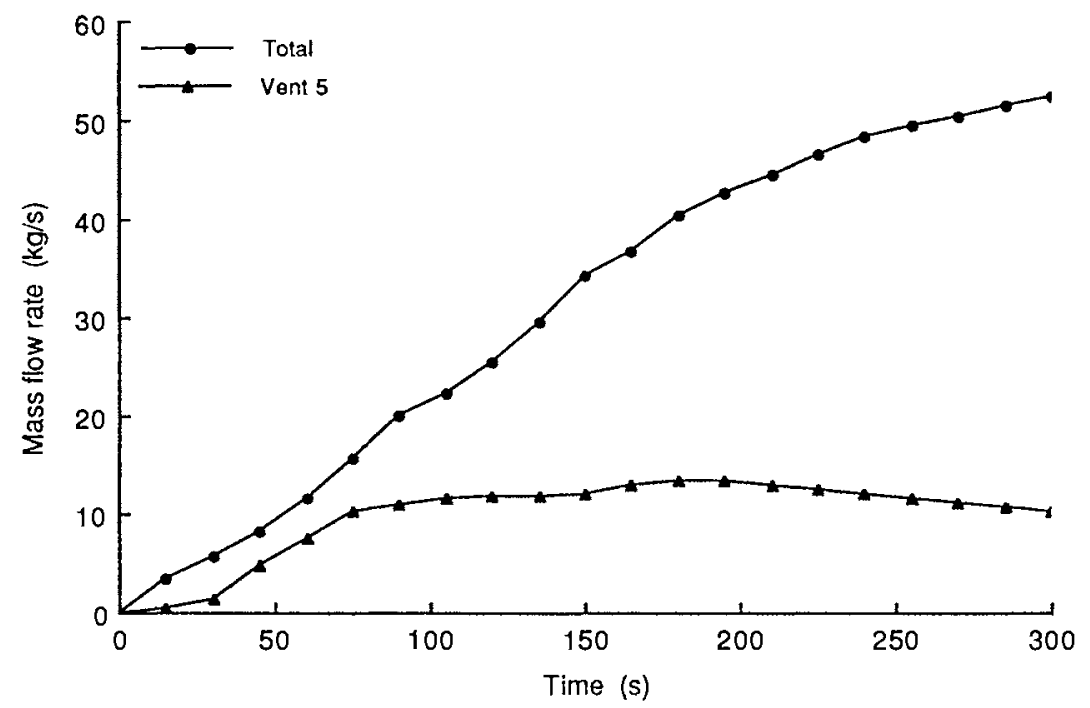

FIGURE 3. Mass flow rate from the roof vents 


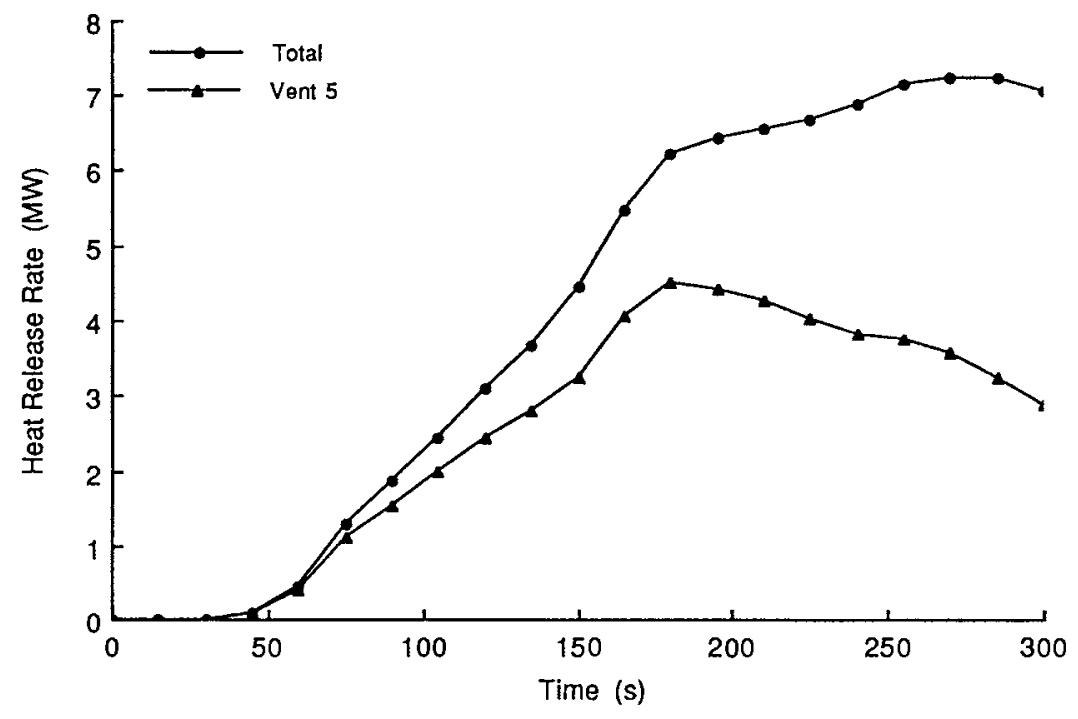

PIGURR 4. Convected heat release rate from the roof vents

Table 1 summarises the emission parameters at the roof vents after five minutes. Values are given for the individual vents and for the total roof area. Quoted combustion product mass fractions, temperatures and densities are 'area averaged' over the grid cells at each vent. The mass fractions are quite low, with entrained air forming the bulk of the emission. The vertical velocity is the maximum value over the grid cells at the vent.

For the above case there was net outflow from all nine vents. This was balanced approximately by 'cold air' entrained in through the doors. The mass inflow rates through doors 1 and 2 , after five minutes, were $23.7 \mathrm{~kg}$ $\mathrm{s}^{-1}$ and $23.2 \mathrm{~kg} \mathrm{~s}^{-1}$ respectively. The discrepancy between the total inflow and outflow masses appears to be due mainly to the transient nature of the simulation. The mass source from the fire accounts only for $1.4 \mathrm{~kg} \mathrm{~s}^{-1}$.

In the studies with 48 roof vents open across the entire roof, mass inflow was predicted at a few of the vents, illustrating that the coupling between internal and external flow can be very complicated. This awaits further investigation. 
TABLE 1. Emission parameters after five minutes at the roof vents

\begin{tabular}{|c|c|c|c|c|c|c|c|c|c|c|}
\hline Parameter & 1 & 2 & 3 & $\begin{array}{l}\text { Value } \\
4\end{array}$ & $\begin{array}{c}\text { at } \\
5\end{array}$ & $\begin{array}{c}\text { vents } \\
6\end{array}$ & 7 & 8 & 9 & All vents \\
\hline $\begin{array}{l}\text { Mass flow } \\
\text { rate } \\
\left(\mathrm{kg} \mathrm{s}^{-1}\right)\end{array}$ & 5.1 & 5.2 & 5.8 & 5.5 & 10.1 & 4.8 & 6.3 & 4.7 & 4.8 & 52.3 \\
\hline $\begin{array}{l}\text { Convected } \\
\text { heat release } \\
\text { (MW) }\end{array}$ & .51 & .59 & .65 & .70 & 2.88 & .35 & .79 & .27 & .31 & 7.06 \\
\hline $\begin{array}{l}\text { Temperature } \\
\text { (K) }\end{array}$ & 390 & 400 & 400 & 410 & 490 & 362 & 413 & 350 & 353 & 397 \\
\hline $\begin{array}{l}\text { Density } \\
\left(\mathrm{kg} \mathrm{m}^{-3}\right)\end{array}$ & .91 & .89 & .88 & .86 & .77 & .98 & .86 & 1.01 & 1.00 & 0.91 \\
\hline $\begin{array}{l}\text { Combustion } \\
\text { product } \\
\text { mass faction }\end{array}$ & .035 & .039 & .039 & .042 & .074 & .025 & .044 & .021 & .022 & .038 \\
\hline $\begin{array}{l}\text { Max vertical } \\
\text { velocity } \\
\left(\mathrm{m} \mathrm{s} \mathrm{s}^{-1}\right)\end{array}$ & 1.7 & 1.7 & 1.8 & 2.0 & 10.4 & 1.8 & 2.1 & 1.4 & 1.4 & 10.4 \\
\hline $\begin{array}{l}F \\
\left(m^{4} s^{-3}\right)\end{array}$ & 4.5 & 4.9 & 5.6 & 5.8 & 14.8 & 3.1 & 6.8 & 2.5 & 2.7 & 46.0 \\
\hline $\begin{array}{l}\mathrm{H} \\
\left(\mathrm{m}^{4} \mathrm{~s}^{-2}\right)\end{array}$ & 6.0 & 6.3 & 7.9 & 7.4 & 40.2 & 5.0 & 9.6 & 4.5 & 4.8 & 91.7 \\
\hline
\end{tabular}

\section{External Hodelling}

The external dispersion simulation used the above data to define flux sources, at the roof vents, releasing mass, momentum and heat at a constant rate. Figure 5 indicates the predicted external flow field in the direction of the wind $\left(6.2 \mathrm{~m} \mathrm{~s}^{-1}\right.$ at roof height), showing the emission being carried downwind.

Computer predictions were made of emission concentration as a function of downwind distance and height above ground. This allows an assessment of whether the dispersed plume is potentially a severe local hazard or a less severe 'diluted' hazard further away. Results for ground level concentration against downwind distance and concentration as a function of height have been generated. Before presenting these results, definitions are given for three dimensionless measurements used widely in dispersion modelling studies.

The dimensionless concentration, $K$, of the emission gases is defined [8] as 
$K=\frac{C U L^{2}}{E}$

where $C$ is the actual atmospheric concentration, $E$ is the total emission rate at the roof vents (mass flow rate of emission gases) and $U$ is the wind velocity at roof height $L$.

The buoyancy and momentum of an emission are characterised by the buoyancy and momentum flux numbers

Buoyancy flux number $=\frac{F}{U^{3} L}$

Momentum flux number $=\frac{M}{U^{2} L^{2}}$

where $U$ and $L$ are as above, and $F$ and $M$ are the buoyancy and momentum fluxes defined [8] as

$F=V_{p}\left(\frac{\rho_{a}-\rho_{p}}{\rho_{a}}\right) \frac{g}{\pi} \quad\left(m^{4} s^{-3}\right)$

$M=V_{p} \frac{\rho_{p}}{\rho_{a}} W_{p} \quad\left(m^{4} s^{-2}\right)$

where the variables are defined in the nomenclature.

The values of $F$ and $M$ used for this $8.5 \mathrm{MW}$ fire are, from Table 1, 46.0 $\mathrm{m}^{4} \mathrm{~s}^{-3}$ and $91.7 \mathrm{~m}^{4} \mathrm{~s}^{-2}$ respectively. Expressed as dimensionless buoyancy and momentum flux numbers these are 0.024 and 0.037 respectively.

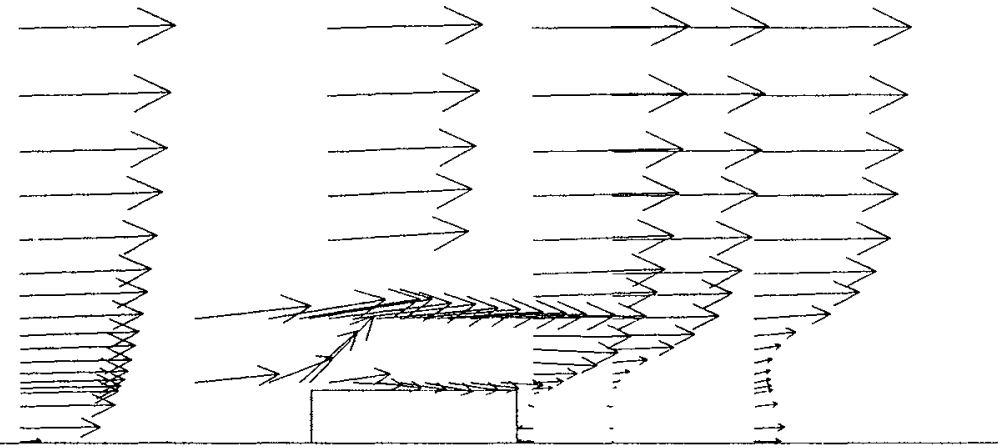

FIGURE 5. Velocity vectors of the external dispersion 
Figure 6 shows the variation in $\mathrm{K}$ with distance downwind from the warehouse. It is compared with the case of a 'neutral' emission, ie zero buoyancy and momentum flux (emission 'seeps' out and is carried away by the external flow field). Figure 7 shows a plot of $K$ against height above ground at a distance $500 \mathrm{~m}$ downwind. Again, a comparison is made against a 'neutral' emission.

The important feature of these results is that the emission has "lifted off" significantly from the ground at a short distance form the warehouse, giving low values of ground level concentration. This contrasts with the neutral emission where the plume is "attached" to the ground.

In the studies conducted so far the predicted concentration values have corresponded to the concentration of the emission as a whole, ie combustion products, entrained air and unburned fuel. However, to assess pollution and health hazards it is necessary to scale the computed concentrations to reflect the concentration of the hazardous substance within the emission. For complicated substances such as pesticides this requires data from small scale combustion experiments (see for example [9]).

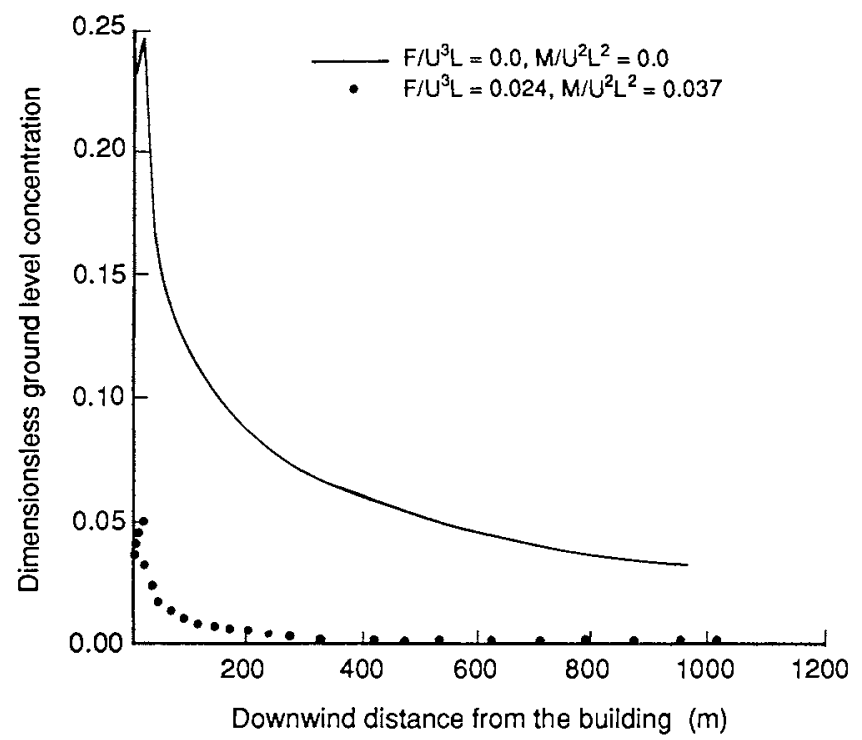

FIGURE 6. Ground level concentration downstream from the warehouse 


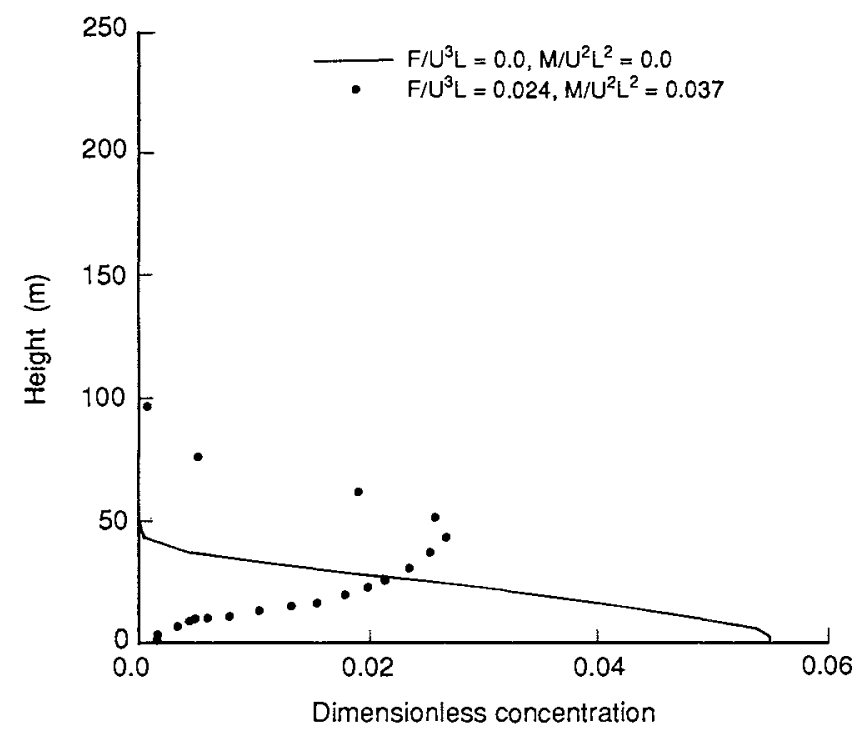

FIGURE 7. Variation in concentration with height above ground $500 \mathrm{~m}$ downstream

\section{DISCUSSION AND CONCLUSIONS}

This work represents a first step in the development of a CFD capability for estimating the dispersion of hazardous substances resulting from warehouse fires. For the case of a single high-rack fire within a warehouse the outflow of hot gases from an array of nine roof vents has been computed. The outflow data have then been used in a dispersion model which has computed the concentration of the emission transported from the building by an external wind.

Further work is required, however, in a number of areas to provide more faithful simulations:

1. To model the transient response of the warehouse, in particular the opening of automatic roof vents and structural failure such as the collapse of skylight panels.

2. To use more representative fire growth curves for pesticide and herbicide storages.

3. To develop closer coupling of the internal and external models. In effect the internal model would be a sub-model of the dispersion model with key data passed between the two models at each time step of a transient simulation. External atmospheric conditions will, in many cases, effect fire development within the building, and hence also the resultant emissions. 
4. To include complex terrain geometries in the dispersion model.

Work is currently in progress to provide this closer coupling of the two models, and to more fully model the transient nature of the problem. This area of work should result eventually in better methods for assessing the hazard, to man and the environment, of fires in buildings housing dangerous substances such as pesticides.

\section{ACKNONLEDGERTENTS}

This work forms part of the Science and Technology for Environmental Protection (STEP) Programme of the Commission of the European Communities (CEC). It is funded jointly by the CEC and the Building Research

Establishment, UK.

- Crown Copyright 1993

\section{REFERENCES}

1. Atkinson, G., "Notes for the use of FIREPEST: A Computer Model of Fire in a Warehouse and the Dispersion of Toxic Products of Combustion", Health and Safety Executive (UK) Report IR/L/FR/90/19, 1990.

2. McQuaid, J., "Industrial Fire Problems: An Overview", Proceedings of the Third International Symposium on Fire Safety Science, pp. 61-81, Elsevier, 1991.

3. You, H.Z. and Kung, H.C., "Strong Buoyant Plumes of Growing Rack Dtorage Fires", Twentieth Symposium (International) on Combustion, pp. 1547-1554, The Combustion Institute, 1984.

4. Cox, G. and Kumar, S., "Field Modelling of Fire in Forced Ventilated Enclosures", Combustion Science and Technology, 52, pp. 7-23, 1987.

5. Markatos, N.C., Pericleous, K. and Simitovic, R., "A

Hydrometeorological Three-dimensional Model of Thermal Energy Releases into Environmental Media", International Journal for Numerical Methods in Fluids, $\underline{7}: 3$, pp. 263-276, 1987.

6. Markatos, N.C., Malin, M.R. and Cox, G., "Mathematical Modelling of Buoyancy-Induced Smoke Flow in Enclosures", International Journal of Heat and Mass Transfer, $25: 1$, pp. 63-75, 1982 .

7. Launder, B.E. and Spalding, D.B., "The Numerical Computation of Turbulent Flows", Computer Methods in Applied Mechanics and Engineering, 3 , pp. 269-289, 1974 .

8. Hall, D.J., Kukadia, V. and Marsland, G. W., "Dispersion of Plumes from Darehouse Fires", CIMAH Safety Reports for Varehouses, Institute of Chemical Engineers North Western Branch, Symposium Papers No 3, Chester UK, 1993.

9. Atkinson, G.T. and Jagger, S.F., "Exposure of Organophosphorus Pesticides to Turbulent Dissusion Flames", Journal of Loss Prevention in the Process Industries, $\underline{5}: 5$, p. 271,1992 . 